\title{
Raising the threshold for hospital admission and endoscopy in upper gastrointestinal bleeding during the COVID-19 pandemic
}

Upper gastrointestinal bleeding (UGIB) is a common cause of hospital admissions worldwide. While health care systems are under significant strain during the COVID-19 pandemic, it is logical to reduce hospital admissions for patients at very low risk of poor outcomes. Additionally, upper gastrointestinal endoscopy is recognized as an aerosol-generating procedure that should be restricted during the pandemic, because of the risk of spreading COVID-19 and the limited availability of personal protection equipment $[1,2]$. Therefore, elective and even urgent endoscopy has been suspended in many centers worldwide. Current guidelines recommend the use of the Glasgow-Blatchford Score (GBS) for predicting the need for hospital-based intervention in patients with UGIB $[3,4]$. Patients with $G B S \leq 1$ are recognized to be at very low risk and can safely be managed as outpatients with no need for inpatient endoscopy [3,4].

Based on data from a large international multicenter study including 3012 consecutive patients with UGIB [5], we have evaluated the outcomes associated with extended low risk GBS thresholds for identifying patients needing hospital admission and endoscopic therapy.
- Table 1 shows the numbers of identified low-risk patients and outcomes for GBS thresholds 0 to $\leq 5$. Use of GBS $\leq 2$ or $\leq 3$ as thresholds for avoiding hospital admission in UGIB would lead to avoidance of admission and in-hospital endoscopy in $26 \%-32 \%$ of all UGIB patients. In patients classified as being at low risk, the risk of needing endoscopic therapy $(3.3 \%-4.1 \%)$, needing surgery or embolization $(0.5 \%)$, death within 30 days $(0.8 \%-1.7 \%)$, and delayed identification of upper gastrointestinal cancer $(0.65 \%$ $0.75 \%$ ) would probably be acceptable in countries with a health care system facing significant strain or potential collapse from COVID-19. If such patients are admitted for other reasons, the very low risk of needing endoscopic therapy suggests endoscopy could be undertaken electively as an outpatient. Consistently with these suggested thresholds, re-analysis of data from a multicenter study of 1555 patients with UGIB found endoscopic therapy was required in $4.2 \%-4.4 \%$ patients with GBS 2 or 3 , but rose to $9.4 \%$ for GBS 4 [6].

Combining extended GBS thresholds with exclusion of patients with major risk factors including systolic blood pressure $<100 \mathrm{mmHg}$, syncope, or liver cirrhosis was not superior to use of GBS $\leq 2-3$ alone. However, clinical judgment would still be required for specific patients. In countries severely affected by COVID19 , we suggest that the low risk threshold for defining UGIB patients who require hospitalization and inpatient endoscopy could be raised to GBS $\leq 2$ or even GBS $\leq 3$. These patients could be treated with high dose oral proton pump inhibitors and evaluated with endoscopy once the epidemic has peaked.

\section{Competing interests}

I.M. Gralnek is a consultant for Motus GI, Boston Scientific, Symbionix, and GI View; he has a financial interest in and is a member of the Medical Advisory Board of MOTUS GI. A.J. Stanley and S.B. Laursen declare that they have no conflicts of interest.

The authors

Stig B. Laursen ${ }^{1}$, Ian M. Gralnek², Adrian J. Stanley ${ }^{3}$

1 Department of Medical Gastroenterology, Odense University Hospital, Odense, Denmark

- Table 1 Outcomes among patients $(n=3012$ [5]) with upper gastrointestinal bleeding and low Glasgow-Blatchford Score (GBS), according to threshold used.

\begin{tabular}{|c|c|c|c|c|c|c|}
\hline \multirow[t]{2}{*}{ GBS threshold } & \multirow{2}{*}{$\begin{array}{l}\text { Patients classified } \\
\text { as low risk, n (\%) }\end{array}$} & \multicolumn{5}{|l|}{ Outcomes, n (\%) } \\
\hline & & $\begin{array}{l}\text { Hemostatic intervention, and/ } \\
\text { or Need for transfusion, and/ } \\
\text { or, Death }\end{array}$ & $\begin{array}{l}\text { Need for } \\
\text { transfusion }\end{array}$ & $\begin{array}{l}\text { Endoscopic } \\
\text { therapy }\end{array}$ & $\begin{array}{l}\text { Surgery/em- } \\
\text { bolization }\end{array}$ & $\begin{array}{l}\text { 30-day } \\
\text { mortality }\end{array}$ \\
\hline 0 & $254(8.7)$ & $5(2.0)$ & $0(0)$ & $3(1.2)$ & $1(0.4)$ & $1(0.4)$ \\
\hline$\leq 1$ & 564 (19) & $19(3.4)$ & $10(1.8)$ & $8(1.4)$ & $2(0.4)$ & $2(0.4)$ \\
\hline$\leq 2$ & $770(26)$ & $45(5.9)$ & $20(2.6)$ & $25(3.3)$ & $4(0.5)$ & $6(0.8)$ \\
\hline$\leq 3$ & $934(32)$ & $72(7.7)$ & $28(3.0)$ & $38(4.1)$ & $5(0.5)$ & $16(1.7)$ \\
\hline$\leq 4$ & $1120(38)$ & $105(9.4)$ & $39(3.5)$ & $60(5.4)$ & $6(0.5)$ & $22(2.0)$ \\
\hline$\leq 5$ & $1299(44)$ & $159(12)$ & $61(4.7)$ & $80(6.2)$ & $7(0.5)$ & $41(3.2)$ \\
\hline
\end{tabular}


2 Ellen and Pinchas Mamber Institute of Gastroenterology, Emek Medical Center, Afula, Israel

3 Department of Gastroenterology, Glasgow Royal Infirmary, Glasgow, United Kingdom

\section{Corresponding author}

\section{S.B. Laursen, MD}

Department of Medical Gastroenterology, Odense University Hospital, 29 Søndre Boulevard, 5000 Odense C, Denmark Fax: +45-66-111328

Stig.laursen@rsyd.dk

\section{References}

[1] Endoscopy activity and COVID-19: BSG and JAG guidance. Updated on: 03 Apr 2020 Accessed: April 8 2020. Available at: https:// www.bsg.org.uk/covid-19-advice/endos- copy-activity-and-covid-19-bsg-and-jagguidance

[2] Gralnek IM, Hassan C, Beilenhoff U et al. ESGE and ESGENA Position Statement on gastrointestinal endoscopy and the COVID19 pandemic. Accessed: May 9 2020. Available at: https://www.esge.com/esge-andesgena-position-statement-on-gastrointestinal-endoscopy-and-the-covid-19-pandemic/

[3] Barkun AN, Almadi M, Kuipers EJ et al. Management of nonvariceal upper gastrointestinal bleeding: Guideline recommendations from the International Consensus Group. Ann Intern Med 2019; 171: 805-822. doi:10.7326/M19-1795

[4] Gralnek IM, Dumonceau JM, Kuipers EJ et al. Diagnosis and management of nonvariceal upper gastrointestinal hemorrhage: European Society of Gastrointestinal Endoscopy (ESGE) Guideline. Endoscopy 2015; 47: a1a46

[5] Stanley AJ, Laine L, Dalton HR et al. Comparison of risk scoring systems for patients presenting with upper gastrointestinal bleed- ing: international multicentre prospective study. BMJ 2017; 356: i6432. doi:10.1136/ bmj.i6432

[6] Stanley AJ, Dalton HR, Blatchford O et al. Multicentre comparison of the Glasgow Blatchford and Rockall scores in the prediction of clinical end-points after upper gastrointestinal haemorrhage. Aliment Pharmacol Ther 2011; 34: 470-475.

doi:10.1111/j.1365-2036.2011.04747.x

Bibliography

Endoscopy 2020; 52: 930-931

DOI 10.1055/a-1202-1374

ISSN 0013-726X

(C) 2020. Thieme. All rights reserved.

Georg Thieme Verlag KG Rüdigerstraße 14,

70469 Stuttgart, Germany 